\title{
PRODUÇÃO DE VIDEIRAS 'NIAGARA BRANCA' E 'CONCORD' SUBMETIDAS A DUAS SAFRAS POR CICLO VEGETATIVO NA DEPRESSÃO CENTRAL DO RIO GRANDE DO SUL
}

\author{
PRODUCTION OF 'NIAGARA BRANCA' AND 'CONCORD' VARIETIES \\ SUBMITTED TO TWO HARVESTS BY SEASON AT DEPRESSÃO CENTRAL OF \\ RIO GRANDE DO SUL
}

\author{
Rafael ANZANELLO' \\ Paulo Vitor Dutra de SOUZA2 \\ Mateus Pereira GONZATTO ${ }^{3}$
}

\begin{abstract}
RESUMO
O manejo adequado da poda permite alterar a fenologia da videira, modificando os períodos de colheita, inclusive com potencial de obtenção de mais de uma safra por ciclo vegetativo. Diante desse potencial avaliou-se uma época de poda seca no inverno (08/08/05) e duas épocas de poda verde (04/11/05 e 02/12/05) nas cultivares Niagara Branca e Concord, ambas Vitis labrusca, visando obter duas safras no mesmo ciclo vegetativo. O experimento foi realizado na safra 2005/2006 em videiras cultivadas em sistema de espaldeira, localizadas em Eldorado do Sul - RS. Variáveis associadas à fenologia, produção por planta, peso dos cachos, sólidos solúveis totais (SST), acidez total titulável (ATT) e relação SST/ATT foram analisadas para as safras obtidas. O ciclo fenológico das plantas podadas no inverno foi de 156 dias para a 'Niagara Branca' e 161 dias para a 'Concord', com colheita realizada em meados de janeiro. Por sua vez, o ciclo fenológico das brotações oriundas das podas verdes realizadas em 04/11/2005 e 02/12/2005 foi, respectivamente, de 127 e 113 dias, para a 'Niagara Branca', e 134 e 120 dias para a 'Concord', com colheitas realizadas em meados do mês de abril. A época de poda verde realizada em 04/11/05 permitiu maior produção por planta e cachos de maior peso, independentemente da cultivar, comparativamente à $02 / 12 / 05$. A qualidade dos frutos foi semelhante entre as safras, mostrando apenas diferenças significativas entre cultivares, expressa numa menor ATT e maior relação SST/ATT para a 'Niagara Branca'.
\end{abstract}

Palavras-chave: Vitis labrusca; fenologia; manejo da poda; segunda colheita.

\begin{abstract}
The adequate pruning management of grapevine permits to change its fenology, modifying the crop periods and creating conditions for two annual harvests. A winter pruning period (08/08/05) and two periods of summer pruning $(04 / 11 /$ 05 and 02/12/05) were evaluated in order to obtain two annual harvests, using Niagara Branca and Concord grape varieties (both Vitis labrusca). This experiment was performed during the 2005/2006 season in grapevines conducted by cordon training in Eldorado do Sul county, Rio Grande do Sul, Brazil. Variables associated to fenology, plant production, weight of grapes, total soluble solids, total titratable acidity and ratio total soluble solids by total titratable acidity related to harvests were analyzed. The fenology of plants pruned in winter was 156 days for 'Niagara Branca' and 161 days for 'Concord', and the harvest was performed around January, 15th. Regarding the summer pruning performed on 04/11/05 and 02/12/05, fenology cycle of shoots was 127 and 113 days for the 'Niagara Branca' and 134 and 120 days for the 'Concord', respectively. Harvest was realized in middle April, 15th. The summer pruning realized in 04/11/05 provided higher production per plant and grapes of higher weight, independent of cultivar, when compared to the 02/12/05 pruning. Fruit quality was similar among the harvests, with significant differences between cultivars expressed by smaller total titratable acidity and higher ratio of total soluble solids by total titratable acidity for the 'Niagara Branca'.
\end{abstract}

Key-words: Vitis labrusca; fenology; pruning management; second harvest.

\footnotetext{
${ }^{1}$ Engenheiro Agrônomo, Mestrando PPGFitotecnia, Departamento de Horticultura e Silvicultura, Faculdade de Agronomia/UFRGS, Bolsista CNPq. Email: ranzanello@yahoo.com.br.

2 Engenheiro Agrônomo, Doutor em Agronomia, Professor do Departamento de Horticultura e Silvicultura, PPGFitotecnia, Faculdade de Agronomia/UFRGS, Bolsista CNPq. Av. Bento Gonçalves, 7712, 91540-000, Caixa Postal 15100, Porto Alegre - RS. E-mail: pvdsouza@ufrgs.br. Autor para correspondência.

${ }^{3}$ Engenheiro Agrônomo, Mestrando PPGFitotecnia, Departamento de Horticultura e Silvicultura, Faculdade de Agronomia/UFRGS, Bolsista CNPq. Email: mpgonzatto@gmail.com
} 


\section{INTRODUÇÃO}

A viticultura tem uma grande importância sócio-econômica e cultural para diversos países. No ano de 2006, esta cultura ocupou mais de 7.399,5 milhões de hectares, com produção de aproximadamente $68.952,7$ milhões de toneladas e produtividade média de $9.318,5 \mathrm{~kg} \mathrm{ha}^{-1}$, segundo dados da FAO (2008).

No Brasil, a produção de uvas se localiza principalmente nas regiões Sul, Sudeste e Nordeste. Nas regiões tropicais, realizam-se tradicionalmente duas ou mais safras de uvas por ano (CAMARGO, 2000). Porém, em regiões de clima temperado, como o Rio Grande do Sul e Santa Catarina, o clima e o manejo adotado propiciam a colheita a uma única época do ano. No caso da 'Niagara' e 'Concord', esta se concentra entre a segunda quinzena de janeiro e segunda quinzena de fevereiro, ocorrendo redução de preço do produto neste período pela alta oferta no mercado (GIOVANINNI, 1999).

Dessa forma, alternativas que visem alterar o perfil da viticultura no Rio Grande do Sul provocando mudanças na estrutura de oferta $e$, conseqüentemente, do mercado interno deste produto, podem trazer vantagens econômicas ao viticultor e de disponibilidade da fruta ao consumidor (SOUZA e FOCHESATO, 2007). Alterações na estrutura de produção, mediante colheitas antecipadas e/ou tardias de uvas de mesa, Vitis labrusca ou Vitis vinifera, por meio do manejo da poda, configuraria um cenário mercadológico distinto ao apresentado atualmente pelo Estado (MANFROI et al., 1996)

A execução de uma poda de inverno sucedida por uma poda verde no verão traria a possibilidade de obtenção de duas safras de uva por ano no Estado, com colheitas em épocas mais favoráveis de mercado. Porém, isso só é potencialmente possível em alguns mesoclimas do Rio Grande do Sul, onde o clima é mais ameno no inverno, em que não ocorram geadas tardias ou precoces (FOCHESATO et al., 2007).

Esse trabalho tem por objetivo avaliar o comportamento produtivo de videiras das cultivares Niagara Branca e Concord submetidas à poda seca no inverno e a diferentes épocas de poda verde, no verão, na região da Depressão Central do Rio Grande do Sul, visando produzir duas safras de uva, em épocas distintas do ano, no mesmo ciclo vegetativo da videira.

\section{MATERIAL E MÉTODOS}

O experimento foi realizado na Estação Experimental Agronômica da Universidade Federal do Rio Grande do Sul, localizada no município de Eldorado do Sul - RS (3005'27"S e 5140'18"O, altitude de $46 \mathrm{~m}$ ). O solo do local é classificado como Argissolo Vermelho Distrófico Típico, de textura argilosa e relevo ondulado, tendo como substrato o granito. Segundo Köppen, o clima da região é classificado como Cfa. A precipitação pluvial anual média é de $1.445,8 \mathrm{~mm}$, a umidade relativa do ar anual média é $77 \%$ e a soma de unidades de frio abaixo de 7,2 ${ }^{\circ} \mathrm{C}$, correspondente aos meses de maio a agosto, é de $250 \mathrm{~h}$. A radiação solar global média é de 12,39 $\mathrm{MJ} \mathrm{m}^{-2} \mathrm{dia}^{-1}$ (BERGAMASCHI et al., 2003).

Para o experimento utilizou-se duas cultivares de videira, a 'Niagara Branca' e a 'Concord', ambas Vitis labrusca, enxertadas sobre o portaenxerto 101-14 Mgt, com 12 anos de idade, conduzidas no sistema tipo espaldeira, com três fios de arame e espaçamento de 1,20 m x 3,00 m.

$O$ delineamento experimental utilizado foi em blocos casualizados, com quatro repetições e duas plantas por parcela, sendo testadas, uma época de poda seca no inverno $(08 / 08 / 2005)$ e duas épocas de poda verde no verão (04/11/2005, 02/12/ 2005), arranjadas em três tratamentos: testemunha, com apenas poda de inverno, poda de inverno + poda verde em 04/11/05 e poda de inverno + poda verde em 02/12/05.

O sistema adotado de poda de inverno foi em cordão esporonado, deixando-se esporões com duas a três gemas, mantendo-se aproximadamente 30-35 gemas por planta. Todas as plantas foram submetidas à quebra de dormência mediante aplicação de cianamida hidrogenada a $2 \%$ imediatamente após a poda de inverno. Já, a poda verde foi feita mediante o desponte do sarmento acima da quarta gema a partir do último cacho, e a eliminação das feminelas, forçando a brotação das gemas produtivas. As plantas testemunhas receberam somente desponte do sarmento imediatamente acima do terceiro fio de arame, o que correspondeu a mais de oito folhas a partir do último cacho.

Avaliou-se, no decorrer do experimento, a duração dos subperíodos fenológicos para cada safra, conforme classificação de BAGGIOLINI (1952), as épocas de colheita, a produção por planta $(\mathrm{kg})$, a massa média dos cachos ( $\mathrm{g})$, o teor de sólidos solúveis totais (SST), a acidez total titulável (ATT) e a relação SST/ATT.

Os subperíodos fenológicos considerados da videira foram: vegetativo, compreendo da poda à brotação e da brotação à floração; e reprodutivo, abrangendo da floração à colheita. Os respectivos intervalos tiveram um acompanhamento com base no balanço hídrico apontado pela diferença entre precipitação $(P)$ e evapotranspiração de referência (E0) (MARCUSSI et al., 2006) e pelo acúmulo de graus-dia (GD), calculado segundo PEDRO JUNIOR et al. (1994).

$$
G D=\sum_{i=1}^{n}(T m-T b)
$$

onde Tm é a temperatura média do $\operatorname{ar}\left({ }^{\circ} \mathrm{C}\right)$, obtida a partir de 24 temperaturas horárias, e Tb é a temperatura base inferior $\left({ }^{\circ} \mathrm{C}\right)$ da videira. A temperatura base inferior utilizada neste cálculo foi de $10^{\circ} \mathrm{C}$, tanto para 'Niagara Branca' como para a 'Concord', de acordo com PEDRO JUNIOR et al. (2004). 
A produção por planta foi obtida pela pesagem dos cachos colhidos em balança eletrônica. A massa média dos cachos foi obtida pela divisão entre a produção por planta e o número de cachos por planta.

O teor de SST foi determinado em refratômetro de mesa, modelo 2 WAJ, a partir de uma amostra de $20 \mu \mathrm{L}$ da mistura contendo mosto, sementes e casca centrifugada a uma rotação de $3000 \mathrm{rpm}$ por $15 \mathrm{~min}$. AATT (cmol L-1) foi determinada por titulação com $\mathrm{NaOH} 0,1 \mathrm{~mol} \mathrm{~L}^{-1}$ e com auxílio de um pHmetro digital DIGIMED até atingir $\mathrm{pH} 8,1$ (CATALUÑA, 1984). A relação SST/ATT foi obtida pela razão entre os SST e a ATT em \% de equivalente ácido tartárico. Para a determinação do SST e da ATT utilizou-se cinco cachos de uva por unidade experimental.

Os resultados com diferenças significativas, pelo teste " $F$ ", na análise de variância, tiveram suas médias submetidas ao teste de Tukey ao nível de significância de $5 \%$ de probabilidade.

\section{RESULTADOS E DISCUSSÃO}

O ciclo fenológico das plantas podadas em 08/08/05 foi de 156 dias para a 'Niagara Branca' e 161 dias para a 'Concord' (Tabelas 1 e 2). Estes ciclos se assemelharam àqueles observados por SOUZA e FOCHESATO (2007), fazendo-se o uso das mesmas cultivares e mesma época de poda de inverno nas condições da Depressão Central do Rio Grande do Sul. Por sua vez, o ciclo fenológico das plantas submetidas à poda verde em 04/11/2005 e 02/12/2005 foram, respectivamente, de 127 e 113 dias para a cultivar Niagara Branca (Tabela 1). A cultivar Concord apresentou um ciclo cerca de sete dias maior do que a 'Niagara Branca', para ambas as épocas de poda verde (Tabela 2). CONTE (1996), trabalhando com a videira 'Niagara Rosada', em ambiente protegido na região da Serra Gaúcha, obteve valor de 126 dias com a execução da poda verde, próximo ao alcançado no presente estudo.

TABELA 1 - Intervalo, em dias; soma de graus-dia, em ํ; e balanço hídrico, em mm; entre os subperíodos fenológicos da videira cv. Niagara Branca, submetida a uma época de poda de inverno e duas épocas de poda verde, em Eldorado do Sul - RS.

\begin{tabular}{|c|c|c|c|c|c|c|c|c|c|}
\hline \multirow{3}{*}{$\begin{array}{l}\text { Subperíodos } \\
\text { fenológicos }\end{array}$} & \multicolumn{3}{|c|}{ Poda de inverno } & \multicolumn{6}{|c|}{ Poda verde } \\
\hline & \multicolumn{3}{|c|}{$08 / 08 / 05$} & \multicolumn{3}{|c|}{$04 / 11 / 05$} & \multicolumn{3}{|c|}{$02 / 12 / 05$} \\
\hline & Intervalo ${ }^{(1)}$ & $\mathrm{SGD}^{(2)}$ & $P-E_{0}{ }^{(3)}$ & Intervalo & SGD & $P-E_{0}$ & Intervalo & SGD & $P-E_{0}$ \\
\hline Poda/Brotação & 28 & 127,7 & 133,9 & 18 & 192,9 & $-25,1$ & 15 & 135,8 & $-62,0$ \\
\hline Brotação/Floração & 37 & 227,7 & 245,2 & 33 & 297,3 & $-111,5$ & 30 & 402,3 & $-68,4$ \\
\hline Floração/Colheita & 91 & 1067,4 & 153,3 & 76 & 1042,8 & $-125,8$ & 68 & 1064,0 & $-85,5$ \\
\hline Total do Ciclo & 156 & 1422,8 & 532,4 & 127 & 1533,0 & $-277,4$ & 113 & 1602,1 & $-215,5$ \\
\hline
\end{tabular}

TABELA 2 - Intervalo, em dias; soma de graus-dia, em ํ; e balanço hídrico, em mm; entre os subperíodos fenológicos da videira cv. Concord, submetida a uma época de poda de inverno e duas épocas de poda verde, em Eldorado do Sul - RS.

\begin{tabular}{|c|c|c|c|c|c|c|c|c|c|}
\hline \multirow{3}{*}{$\begin{array}{l}\text { Subperíodos } \\
\text { fenológicos }\end{array}$} & \multicolumn{3}{|c|}{ Poda de inverno } & \multicolumn{6}{|c|}{ Poda verde } \\
\hline & \multicolumn{3}{|c|}{$08 / 08 / 05$} & \multicolumn{3}{|c|}{$04 / 11 / 05$} & \multicolumn{3}{|c|}{$02 / 12 / 05$} \\
\hline & Intervalo ${ }^{(1)}$ & $\mathrm{SGD}^{(2)}$ & $P-E_{0}{ }^{(3)}$ & Intervalo & SGD & $P-E_{0}$ & Intervalo & SGD & $P-E_{0}$ \\
\hline Poda/Brotação & 25 & 118,1 & 137,5 & 15 & 152,7 & $-21,3$ & 12 & 135,8 & $-51,0$ \\
\hline Brotação/Floração & 35 & 190,8 & 229,6 & 31 & 382,2 & $-126,9$ & 29 & 402,3 & $-92,6$ \\
\hline Floração/Colheita & 101 & 1188,0 & 141,3 & 88 & 1204,2 & $-152,8$ & 79 & 1064,0 & $-103,8$ \\
\hline Total do Ciclo & 161 & 1496,9 & 508,4 & 134 & 1739,1 & $-301,0$ & 120 & 1602,1 & $-241,4$ \\
\hline
\end{tabular}


O maior ciclo da cultivar Concord nas duas safras deveu-se basicamente a um maior período entre a floração e a colheita, visto que nos subperíodos anteriores seus intervalos foram menores àqueles comparados à cultivar Niagara Branca (Tabelas 1 e 2).

A redução do ciclo fenológico da segunda safra em relação à primeira é conseqüência das temperaturas mais elevadas ocorridas durante 0 desenvolvimento das plantas submetidas à poda verde. Como a videira é geralmente condicionada pela disponibilidade térmica para completar seu ciclo (LEÃO e SILVA, 2003), a temperatura média mais alta nos meses que precederam à segunda colheita foi um dos principais fatores responsáveis pelo encurtamento do seu ciclo de produção.

O acúmulo térmico da poda de inverno à primeira colheita foi de 1422,8 e 1496,9 graus-dia para as cultivares Niagara Branca e Concord, respectivamente (Tabelas 1 e 2), valores próximos àqueles encontrados por SCHIEDECK et al. (1997) no Estado do Rio Grande do Sul, trabalhando a cultivar Niagara Rosada em época semelhante de poda de inverno. Durante o ciclo da segunda safra, no caso da videira 'Concord', houve a necessidade de um maior acúmulo térmico verificado principalmente pelo aumento do subperíodo entre brotação e floração (Tabela 2). Esse aumento provavelmente esteja associado a um déficit hídrico de cerca de $100 \mathrm{~mm}$ quando comparado a um excesso hídrico superior a $200 \mathrm{~mm}$ no primeiro ciclo
(Tabela 2). Segundo TEIXEIRA et al. (1999), tanto a deficiência como o excesso hídrico afetam de maneira marcante o comportamento dos estádios fenológicos da cultura da videira.

Para a 'Niagara Branca' não se percebeu significativos acréscimos na necessidade térmica entre o ciclo da primeira safra e o da segunda safra (Tabela 1).

Os frutos das plantas podadas no inverno foram colhidos em 11/01/06 para a cv. Niagara Branca e em 16/01/06 para a cv. Concord, mostrando que essas cultivares apresentaram um ciclo mais curto quando cultivadas em mesoclimas mais quentes como o da região da Depressão Central, comparativamente a região tradicional da Encosta Superior do Nordeste do Rio Grande do Sul, que usualmente tem a colheita concentrada entre a segunda quinzena de janeiro e a segunda quinzena de fevereiro (MANFROI et al., 1996). Já para as plantas submetidas a poda verde, obteve-se uma colheita em 11/03/06 para a 'Niagara Branca' e 18/ 03/06 para a 'Concord', para as podadas em 04/11/ 05 . Para as plantas podadas em $02 / 12 / 05$, as colheitas foram realizadas em $25 / 03 / 06$ para a 'Niagara Branca' e 01/04/06 para a 'Concord', possibilitando obter uvas tardias com maior valorização de mercado, no período de entressafra (Tabela 3). SOUZA e FOCHESATO (2007) também lograram colheitas entre março e abril com a execução da poda verde, possibilitando ampliar o período de oferta da fruta no mercado.

TABELA 3 - Períodos de colheita em videiras 'Niagara Branca' e 'Concord' submetidas à poda verde, em Eldorado do Sul - RS.

\begin{tabular}{|c|c|c|c|c|}
\hline \multirow{3}{*}{ Poda verde } & \multicolumn{4}{|c|}{ Épocas de colheita } \\
\hline & \multicolumn{2}{|c|}{ Niagara Branca } & \multicolumn{2}{|c|}{ Concord } \\
\hline & $1^{a}$ safra & $2^{\mathrm{a}}$ safra & $1^{\text {a }}$ safra & $2^{a}$ safra \\
\hline $1^{\text {a }}$ época $(04 / 11 / 05)$ & \multirow{2}{*}{$11 / 01 / 06$} & $11 / 03 / 06$ & \multirow{2}{*}{$16 / 01 / 06$} & $18 / 03 / 06$ \\
\hline $2^{\text {a }}$ época $(02 / 12 / 05)$ & & $25 / 03 / 06$ & & $01 / 04 / 06$ \\
\hline
\end{tabular}

A antecipação da colheita da 'Niagara Branca' em uma semana, tanto na primeira, como na segunda safra em relação à 'Concord', deveuse, provavelmente, a características genéticas inerentes as cultivares (MANDELLI et al., 2003).

$\mathrm{Na}$ Tabela 4 observa-se que a época de poda verde realizada em 04/11/05 proporcionou maior produção por planta e maior massa média de cachos para ambas as cultivares, com uma produtividade equivalente a $4.139 \mathrm{~kg} \mathrm{ha}^{-1}$ para a 'Niagara Branca' e $2.194 \mathrm{~kg} \mathrm{ha}^{-1}$ para a 'Concord'. Segundo GIOVANINNI (1999) o rendimento da safra normal para essas cultivares no Estado do Rio Grande do Sul, obtida através da poda seca no inverno, é de 15 a $20 \mathrm{t} \mathrm{ha}^{-1}$. Com a produção oriunda da prática da poda verde, um incremento na produção total anual de uva seria obtido pelo viticultor.

O fraco desempenho produtivo das plantas submetidas à poda verde tardia pode estar associado à inibição da brotação de suas gemas, provavelmente devido à ocorrência de um período expressivo de déficit hídrico, no final da primavera e início do verão, compreendendo o período entre a poda à brotação das plantas podadas em 02/12/05 (Tabelas 1 e 2). À semelhança desse experimento, SCHIEDECK (1996) também verificou baixa brotação das gemas em 'Niagara Rosada' como causa da deficiência hídrica do solo.

Nas plantas despontadas acima do terceiro fio de arame também houve brotação, floração e frutificação, embora insignificante se comparada àquelas podadas acima da quarta folha do último cacho (Tabela 4). A produção nas plantas testemunha não seria esperada, todavia a colheita realizada na cv. Niagara Branca e na cv. Concord, nesse tratamento, justifica-se pelo estímulo provocado pelo desponte acima do terceiro fio de arame, convertendo gemas apicais vegetativas em floríferas, associada a uma intensa realização de desbrota ao longo do experimento. 
TABELA 4 - Produção média por planta e peso médio do cacho na segunda colheita da cv. Niagara Branca e da cv. Concord submetidas a duas épocas de poda verde, em Eldorado do Sul - RS.

\begin{tabular}{|c|c|c|c|c|c|c|}
\hline \multirow{2}{*}{ Cultivar } & \multicolumn{3}{|c|}{ Produção média (kg planta ${ }^{-1}$ ) } & \multicolumn{3}{|c|}{ Massa média $\left(\mathrm{g} \mathrm{cacho}^{-1}\right)$} \\
\hline & Test & $1^{\text {a }}$ época & $2^{\text {a }}$ época & Test & $1^{\text {a }}$ época & $2^{\text {a }}$ época \\
\hline Niagara Branca & $0,14 \mathrm{aB}^{(1)}$ & $1,49 \mathrm{aA}$ & $0,35 \mathrm{aB}$ & $71 \mathrm{aB}$ & $109 \mathrm{aA}$ & $79 \mathrm{aB}$ \\
\hline Concord & $0,05 \mathrm{bB}$ & $0,79 \mathrm{bA}$ & $0,21 \mathrm{bB}$ & $32 \mathrm{bB}$ & $52 \mathrm{bA}$ & $34 \mathrm{bB}$ \\
\hline DMS colunas & & 0,08 & & & 23,23 & \\
\hline DMS linhas & & 0,33 & & & 17,88 & \\
\hline CV (\%) & & 20,97 & & & 19,34 & \\
\hline
\end{tabular}

(1) Médias seguidas pela mesma letra, minúsculas na coluna e maiúsculas na linha, não diferem significativamente pelo teste de Tukey a 5\% de probabilidade. DMS = diferença mínima significativa pelo teste de Tukey a $5 \%$. CV = coeficiente de variação.

Com relação à análise qualitativa, verificase, na Tabela 5, que os frutos submetidos à poda verde não apresentaram diferenças significativas nos teores de sólidos solúveis totais e acidez total titulável, se comparados com os frutos oriundos da poda seca. Este comportamento pode ser explicado pela boa insolação ocorrida ao longo da maturação em ambas as safras, pois em anos anteriores percebeu-se uma redução nos SST e acréscimo na acidez nos frutos colhidos durante os meses de março/abril, comparativamente aos colhidos no mês de janeiro (FOCHESATO et al., 2007).

TABELA 5 - Características químicas da primeira e segunda safras das cultivares Niagara Branca e Concord, em Eldorado do Sul - RS.

\begin{tabular}{|c|c|c|c|c|c|c|}
\hline \multirow{2}{*}{ Cultivar } & \multicolumn{2}{|c|}{ SST $^{(1)}$ (ํㅏix) } & \multicolumn{2}{|c|}{$\operatorname{ATT}^{(2)}\left(\mathrm{cmol} \mathrm{L}^{-1}\right)$} & \multicolumn{2}{|c|}{ SST/ATT } \\
\hline & $1^{a}$ safra & $2^{a}$ safra & $1^{\mathrm{a}}$ safra & $2^{a}$ safra & $1^{\text {a }}$ safra & $2^{a}$ safra \\
\hline Niagara Branca & $16,67 \mathrm{aA}^{(3)}$ & $17,62 \mathrm{aA}$ & $7,70 \mathrm{bA}$ & $8,49 \mathrm{bA}$ & 17,36 aA & $16,62 \mathrm{aA}$ \\
\hline Concord & $15,28 \mathrm{aA}$ & $16,25 \mathrm{aA}$ & $10,64 \mathrm{aA}$ & $10,61 \mathrm{aA}$ & $11,48 \mathrm{bA}$ & $12,21 \mathrm{bA}$ \\
\hline DMS colunas & \multicolumn{2}{|c|}{3,28} & \multicolumn{2}{|c|}{2,09} & \multicolumn{2}{|c|}{3,14} \\
\hline DMS linhas & \multicolumn{2}{|c|}{2,35} & \multicolumn{2}{|c|}{1,76} & \multicolumn{2}{|c|}{2,17} \\
\hline CV (\%) & \multicolumn{2}{|c|}{12,38} & \multicolumn{2}{|c|}{14,52} & \multicolumn{2}{|c|}{15,74} \\
\hline
\end{tabular}

\footnotetext{
(1) Sólidos solúveis totais. ${ }^{(2)}$ Acidez total titulável. ${ }^{(3)}$ Médias seguidas pela mesma letra, minúsculas na coluna e maiúsculas na linha, não diferem significativamente pelo teste de Tukey a $5 \%$ de probabilidade. DMS = diferença mínima significativa pelo teste de Tukey a $5 \%$. CV = coeficiente de variação.
}

A qualidade dos frutos, expressa na relação SST/ATT, foi maior para a 'Niagara Branca', devido ao seu menor teor de acidez comparativamente à 'Concord'. A relação SST/ATT mostrou-se insatisfatória para a cultivar Concord, ficando aquém do desejável para o seu consumo in natura, cuja faixa aceitável situa-se, no mínimo, entre 15 e 16 (CAMARGO, 1994). Já, para a 'Niagara Branca', valores em torno de 17 foram verificados para ambas as safras.

\section{CONCLUSÕES}

1) A execução de uma poda de inverno associada a uma poda verde no verão permite a obtenção de duas safras de uva por ciclo vegetativo da cultura, em épocas distintas do ano.

2) O potencial produtivo de uma segunda safra oriunda da poda verde depende da cultivar empregada e da época em que a mesma é realizada.

\section{AGRADECIMENTOS}

Agradecemos a Universidade Federal do Rio Grande do Sul e ao Programa de Pós-Graduação em Fitotecnia, ao CNPq e CAPES pelo apoio financeiro e concessão de bolsa de estudo. 


\section{REFERÊNCIAS}

1. BAGGIOLINI, M. Les stades repères dans le développement annuel de la vigne et leur utilisation pratique. Revue Romande d'Agriculture, de Viticulture et d'Arboriculture, v. 8, p. 4-6, 1952.

2. BERGAMASCHI, H.; GUADAGNIN, M. R.; CARDOSO, L. S.; SILVA, M. I. G. da. Clima da Estação Experimental da UFRGS (e região de abrangência). Porto Alegre: UFRGS, 2003. 78 p.

3. CAMARGO, U. A. Uvas do Brasil. Brasília: EMBRAPA-SPI, 1994. 90 p.

4. CAMARGO, U. A. Grape breeding for the subtropical and tropical regions of Brazil. Acta Horticulturae, v. 2, n. 528, p. $473-477,2000$.

5. $\quad$ CATALUÑA, E. Uvas e vinhos. Globo: Rio de Janeiro, 1984. 230 p.

6. CONTE, A. Comportamento da videira Niágara Rosada submetida à poda de verão, sob estufa plástica em Bento Gonçalves, RS. 70 f. Dissertação (Mestrado em Fitotecnia - Sistemas de Cultivo e Tecnologias Agrícolas) Curso de Pós-Graduação em Fitotecnia, Setor de Ciências Agrárias, Universidade Federal do Rio Grande do Sul, Porto Alegre, 1996.

7. FOCHESATO, M. L.; SOUZA, P. V. D. de; AGOSTINI, S. Obtenção de duas safras por ciclo vegetativo pelo manejo da poda. Revista Agropecuária Catarinense, v. 20, n. 1, p. 53-57, 2007.

8. FAO - FOOD AND AGRICULTURE ORGANIZATION OF THE UNITED NATIONS. Produção e área cultivada de uvas no mundo. Disponível em: <http://faostat.fao.org/site/526/default.aspx>. Acesso em 17/01/2008

9. GIOVANINNI, E. Produção de uvas para vinhos, suco e mesa. Porto Alegre: Renascença, 1999. 364 p.

10. LEÃO, P. C. S. de; SILVA, E. E. G. Caracterização fenológica e requerimentos térmicos de variedades de uvas sem sementes no Vale do São Francisco. Revista Brasileira de Fruticultura, v. 25, n. 3, p. 379-382, 2003.

11. MANFROI, V.; MARODIN, G. A. B.; SEIBERT, E.; ILHA, L. L. H.; MOLINOS, P. R. Quebra de dormência e antecipação da colheita em videira cv. Niágara Rosada. Revista Brasileira de Fruticultura, v. 18, n. 1, p. 65-74, 1996.

12. MANDELLI, F.; BERLATTO, M. A.; TONIETTO, J.; BERGAMASCHI, H. Fenologia da videira na Serra Gaúcha. Pesquisa Agropecuária Gaúcha, v. 9, n. 1-2, p. 129-144, 2003.

13. MARCUSSI, F. F. N.; SALGADO, E.; WENDLAND, E. Balanço hídrico climatológico comparativo para a cidade de Quillota (Chile) com estimativas de evapotranspiração obtidas pelos métodos de Penman-Monteith e pelo tanque classe A. Irriga, v. 11, n. 43, p. 469-476, 2006.

14. PEDRO JUNIOR, M. J.; HERNANDES, J. L.; PEZZOPANE, J. R. M.; BARDIN, L. Estimativa do crescimento e desenvolvimento para a videira 'Niagara Rosada' conduzida em espaldeira. Revista Brasileira de Agrometeorologia, v. 12, n. 1, p. 67-74, 2004.

15. PEDRO JUNIOR, M. J.; SENTELHAS, P. C.; POMMER, C. V., MARTINS, F. P. Determinação da temperatura-base, grausdia e índice biometeorológico para a videira 'Niagara Rosada'. Revista Brasileira de Agrometeorologia, v. 2, p. 5156,1994

16. SCHIEDECK, G. Ecofisiologia da videira e qualidade de uma Niágara Rosada conduzida sob estufa de plástico. Porto Alegre: 111 f. Dissertação (Mestrado em Fitotecnia - Relação Clima - Planta) - Curso de PósGraduação em Fitotecnia, Setor de Ciências Agrárias, Universidade Federal do Rio Grande do Sul, 1996.

17. SCHIEDECK, G.; MIELE, A.; BARRADAS, C. I. N.; MANDELLI, F. Fenologia da videira 'Niagara Rosada' cultivada em estufa e à céu aberto. Revista Brasileira de Agrometeorologia, v. 5, n. 2, p. 199-206, 1997.

18. SOUZA, P. V. D. de; FOCHESATO, M. L. Emprego da poda verde para obtenção de duas safras por ciclo vegetativo em 'Niagara Branca'. Bragantia, v. 66, n. 4, p. 527-533, 2007.

19. TEIXEIRA, A. H. C.; AZEVEDO, P. V. de; SILVA, B. B. da; SOARES, J. M. Consumo hídrico e coeficiente da cultura da videira na região de Petrolina, PE. Revista Brasileira de Engenharia Agrícola e Ambiental, v. 3, n. 3, p. 413-416, 1999.

Recebido em 19/03/2008

Aceito em 30/05/2008 
